\title{
Pathogens and Related Diseases in Non-European Cephalopods: Asia. A Preliminary Review
}

\author{
Jing Ren, Xiaodong Zheng, Yaosen Qian, and Qingqi Zhang
}

\begin{abstract}
Parasitic diseases and other abnormalities play critical roles in causing morbidity in the majority of Cephalopoda. However, to date, reports of cephalopod diseases from Asia are scarce and lack detailed information on the description of specific characters. This paper presents a brief overview of various pathogens and produced diseases in Asian cephalopods, including coccidiosis by Aggregata, Anisakiasis, infection by the copepods Octopicola, and other abnormalities such as edema and broken skin. The coccidian Aggregata sp. that infects the definitive host Amphioctopus fangsiao is a heteroxenous parasite transmitted through the food web. Anisakids play an important role in Asia as parasitic disease for cephalopods and it is even transmitted to humans. Concerning the infection by copepods, Octopicola sp. is the only species of the family Octopicolidae reported from North Pacific waters. Other abnormalities like edema or broken skin may have been the result of bacterial infections, so that abnormalities could cause the degeneration and death observed in A. fangsiao.
\end{abstract}

\section{Keywords}

Cephalopoda • Pathology • Diseases • Amphioctopus fangsiao • Aggregata • Anisakis • Octopicola • Asian waters

J. Ren $\cdot$ X. Zheng $(\bowtie)$

Institute of Evolution \& Marine Biodiversity, Ocean University of China, Qingdao 266003, China

e-mail: xdzheng@ouc.edu.cn

J. Ren

e-mail: renjing@stu.ouc.edu.cn

J. Ren $\cdot$ X. Zheng

Key Laboratory of Mariculture, Ministry of Education, Ocean University of China, Qingdao 266003, China

Y. Qian

Ganyu Institute of Fishery Science, Lianyungang 222100, China e-mail: gysks6089@163.com

\section{Q. Zhang}

Ganyu Jiaxin Fishery Technical Development Co., Ltd., Lianyungang 222100, China

e-mail: lygjx158@163.com

\subsection{Introduction}

Cephalopoda is the most complex in the invertebrate phyla. Cephalopods include exclusively marine animals that live in all oceans of the world except the Black Sea. In Asia, many cephalopods are important economic species for human beings. Octopods were reported the highest production for 2010, at 217,506 tones, while European production of octopuses was only 42,945 tones (Norman et al. 2014), which are also one of the most important commercial cephalopod groups in China (Zheng et al. 2014; Xu and Zheng 2018). Cuttlefish, such as Sepia pharaonis and Sepiella japonica, were also an important fishery in the northern part of the Indian Ocean and southeastern Asia 


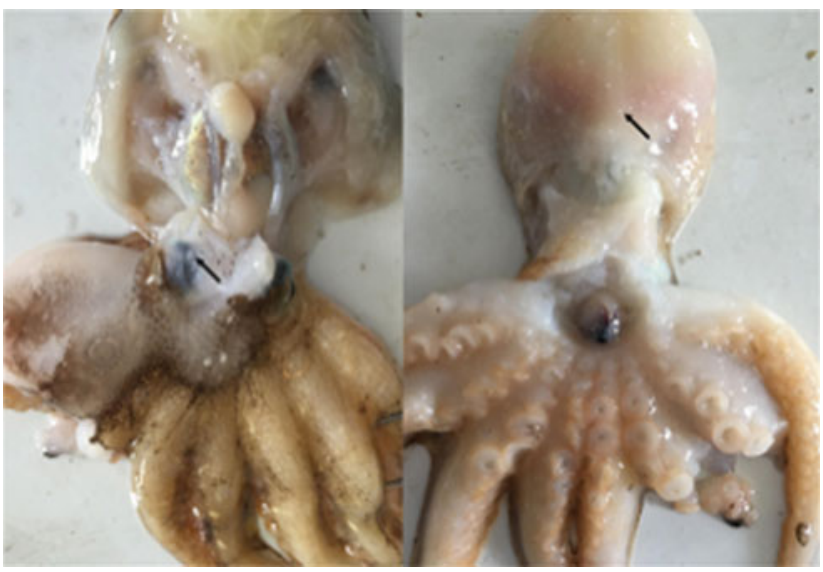

Fig. 18.1 Distribution of parasites on Amphioctopus fangsiao. Arrows showing disseminated cysts in the epidermis

(Nesis, Yin et al. 2018). However, to date, reports of cephalopod diseases from Asia are scarce and lack of detailed information on the description of specific characters.

\subsection{Aggregata Sp.}

Cephalopods are specifically infected by coccidians of the genus Aggregata, which were heteroxenous parasites transmitted through the food web. Sexual stages (including gamogony and sporogony) occur inside the digestive tract of the definitive cephalopod host (Dobell 1925; Gestal et al. 2002). Coccidian infection at pathological level has not been previously reported in Asia and data of its prevalence and distribution are currently scarce. Protozoan parasites of the genus Aggregata affecting Amphioctopus fangsiao in natural environment have been associated with large-scale concentrated deaths occurred in the process of artificial temporarily culture facility in China. White cysts were found in the body surface representing the $43 \%$ of the total number of $A$. fangsiao inspected (95/220) (unpublished data) (Fig. 18.1).
Histological sections of intestinal tissue revealed destruction of the organ architecture and substitution of the tissue by parasite cysts (Fig. 18.2a). Through histological sections observation, the oocysts were spherical, in the range of $249.75-501.75 \mu \mathrm{m}$ (mean $360.76 \pm 70.39 \mu \mathrm{m}$ ) and $116.84-350.87 \mu \mathrm{m}$ (mean $231.67 \pm 74.89 \mu \mathrm{m}) \quad(n=20)$ with plenty of sporocysts in each oocyst. The size of sporocysts was measured as follows: 17.69-20.72 $\mu \mathrm{m}$ (mean $19.20 \pm 0.93 \mu \mathrm{m}$ ) by $15.97-20.00 \mu \mathrm{m}$ (mean $18.31 \pm 1.19 \mu \mathrm{m})(n=20)$. The surface of sporocysts was smooth. The histological results are shown in Fig. 18.2b (unpublished data).

\subsection{Anisakidae}

The life cycle of Anisakidae is rather complex involving small crustaceans as the first intermediate host; fishes and cephalopods as the second host; and marine mammals which act as the definitive host (Nesis et al. 1987; dos Santos and Howgate 2011; Sangaran and Sundar 2016). Thus, anisakiasis is a parasitic disease of cephalopods in Asia. In Japan, where raw squids are consumed as an integral part of the Japanese diet, Anisakid transmission to humans has been reported, producing a strong pathology (Oshima 1972; Tomoo and Kliks 1987; Sakanari and Mckerrow 1989). In China, natural infection of Anisakidae larvae was investigated in squids ( 2 species, 29 specimens) caught in the yellow sea and the East China Sea (Koyama 1969).

\subsection{Octopicola}

To date, the genus Octopicola contains five species parasitizing octopuses (Humes 1957, 1963, 1974; Du et al. 2018). Octopicola huanghaiensis (Fig. 18.3) is the first species reported in A. fangsiao and Octopus minor, and the only species of the family Octopicolidae known in Asia (Du et al. 2018).
Fig. 18.2 Histological sections of A. fangsiao intestines infected by Aggregata sp. a Oocysts infecting the intestinal tissue. b Sporocysts inside the oocyst. Scale bars: A, $50 \mu \mathrm{m} \mathrm{B}, 20 \mu \mathrm{m}$
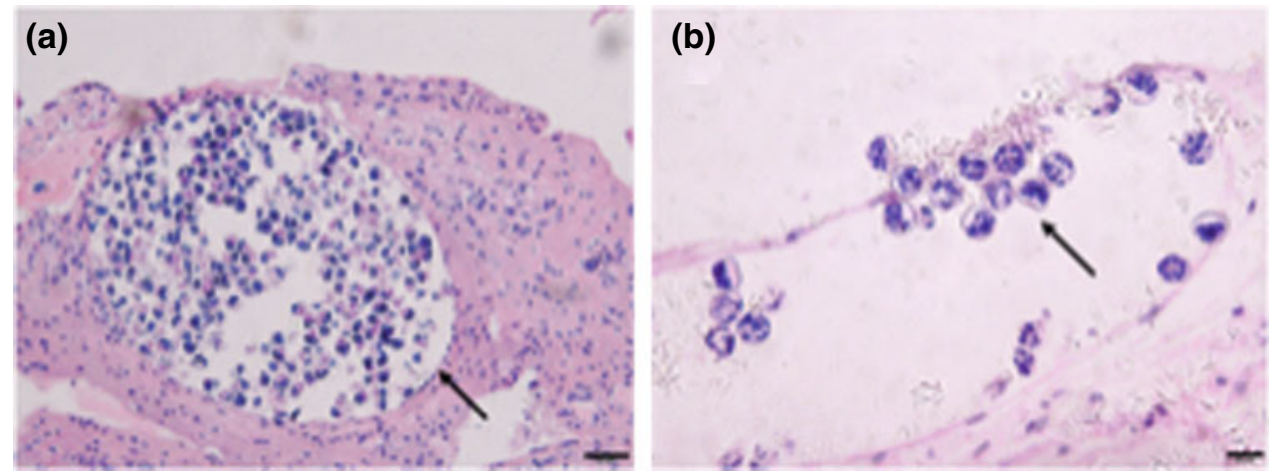

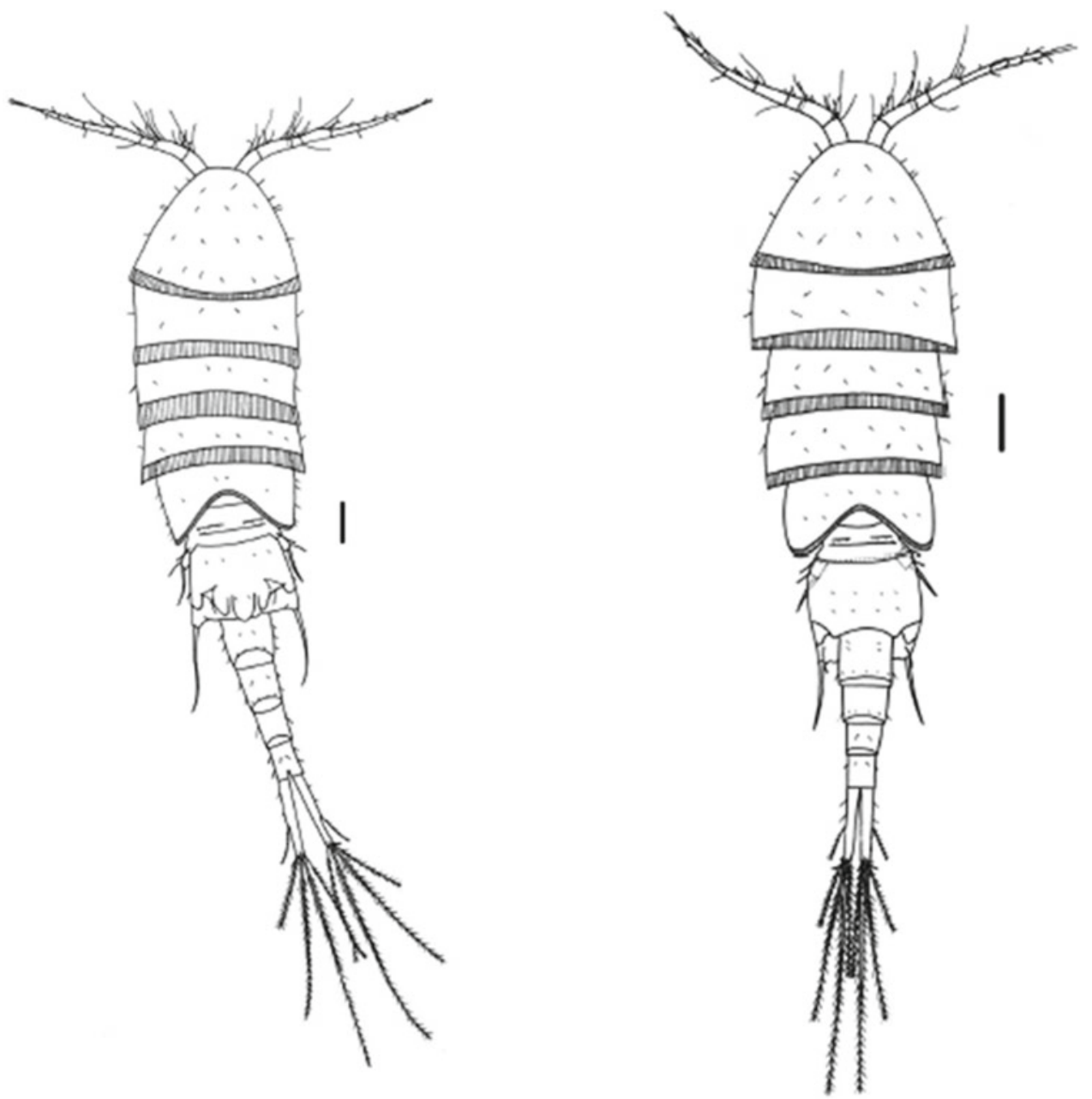

Fig. 18.3 Octopicola huanghaiensis (Scale-bar: $100 \mu \mathrm{m})($ Du et al. 2018)

\subsection{Other Abnormalities}

There are some other abnormalities recorded in Asian octopuses (Fig. 18.4). During our study, wild specimens of A. fangsiao were caught in March 2017 in the Yellow Sea (off Lianyungang, Jiangsu Prov.). The specimens were temporarily reared indoors of the Ganyu Jiaxin Fishery Technical Development Co., Ltd. Individuals were placed in concrete tanks, under the conditions of $11.8^{\circ} \mathrm{C}$, natural photoperiod, as well as plastic suspensors for shelter.

From March 16 to April 2, 1303 dead A. fangsiao individuals were sampled in order to separate males and females. The total number of females was 836 , accounting for $64 \%$ of all deaths. There were 467 males, accounting for $36 \%$ of the total deaths; the female death rate was much higher than that of the male in breeding season, which was extremely weird. Therefore, further examination by gross pathology of 220 dead individuals (body surface) was conducted from March 24 to April 2 to

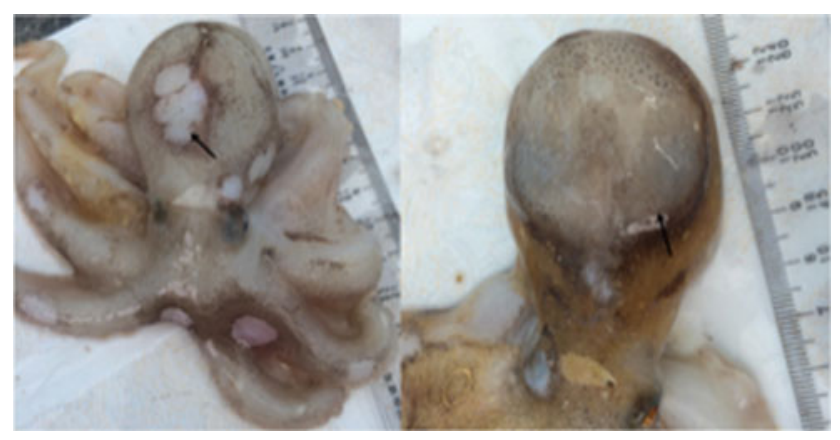

Fig. 18.4 Abnormalities of A. fangsiao. Arrows showing exfoliation of the mantle and edema

analyze the death situation. Eventually, it was found that skin surface of dead individuals includes mainly edema and edema with coccidian (individuals of edema only amount to $16 \%$ of the total number of inspection), broken skin ( $37 \%$ of the total number of inspection), and broken arms (4\% of the total number of inspection). Those 
abnormalities may have been the results of bacterial infection so that abnormalities could cause degeneration and death of the species.

\subsection{Concluding Remarks}

As summarized above, only handful studies have been documented for cephalopod diseases from Asia currently, including coccidiosis by Aggregata sp., Anisakiasis, Octopicola, edema, and broken skin. However, further characterization and functional studies are needed to confirm the effect of diseases on the cephalopods health. Finally, the results obtained in the chapter provide a brief overview of parasitic diseases in Asian waters.

Acknowledgements This work was supported by research grants from National Natural Science Foundation of China (No. 31672257) and the Fundamental Research Funds for the Central Universities (No. 201822022).

\section{References}

Dobell C (1925) The life-history and chromosome cycle of Aggregata eberthi (Protozoa: Sporozoa: Coccidia). Parasitology 17(1):1-136

dos Santos CAL, Howgate P (2011) Fishborne zoonotic parasites and aquaculture: a review. Aquaculture 318(3-4):253-261

Du X, Dong C, Sun SC (2018) Octopicola huanghaiensis n. sp. (Copepoda: Cyclopoida: Octopicolidae), a new parasitic copepod of the octopuses Amphioctopus fangsiao (d'Orbigny) and Octopus minor (Sasaki) (Octopoda: Octopodidae) in the Yellow Sea. Syst Parasitol 95(8-9):905-912
Gestal C, Guerra A, Pascual S, Azevedo C (2002) On the life cycle of Aggregata eberthi and observations on Aggregata octopiana (Apicomplexa, Aggregatidae) from Galicia (NE Atlantic). Eur J Protistol 37(4):427-435

Humes AG (1957) Octopicola superba ng, n. sp., Copepode Cyclopoide parasite d'un Octopus de la Mediterranee. Vie et Milieu Env 8:1-8

Humes AG (1963) Octopicola stocki n. sp. (Copepoda, Cyclopoida), associated with an octopus in Madagascar. Crustaceana 5(4):271280

Humes AG (1974) Octopicola regalis, n. sp. (Copepoda, Cyclopoida, Lichomolgidae) associated with Octopus cyaneus from New Caledonia and Eniwetok Atoll. Bull Mar Sci 24(1):76-85

Koyama T (1969) Morphological and taxonomical studies on Anisakidae larvae found in marine fishes and squids. Jap J Parasitol 18 (5):466-487

Nesis KN, Burgess LA, Levitov BS (1987) Cephalopods of the world: squids, cuttlefishes, octopuses, and allies. TFH, p 351

Norman MD, Finn JK, Hochberg FG, Jereb P, Roper CFE (2014) Cephalopods of the world. An annotated and illustrated catalogue of cephalopod species known to date. FAO Species Catalogue for Fishery Purposes, vol 3(4), pp 1-22

Oshima T (1972) Anisakis and anisakiasis in Japan and adjacent area. Prog Med Parasit, Japan, pp 301-393

Sakanari J, Mckerrow JH (1989) Anisakiasis. Clin Microbiol Rev 2 (3):278-284

Sangaran A, Sundar S (2016) Fish and shell fish borne parasitic infections-a review. Int J Sci Environ Technol 5(5):2954-2958

Tomoo O, Kliks M (1987) Effects of marine mammal parasites on human health. Int J Parasitol 17(2):415-421

Xu R, Zheng XD (2018) Selection of reference genes for quantitative real-time PCR in Octopus minor (Cephalopoda: Octopoda) under acute ammonia stress. Environ Toxicol Phar 60:76-81

Yin SJ, Zhang LM, Zhang LL, Wan JX, Song W, Jiang XM, Park YD, Si YX (2018) Metabolic responses and arginine kinase expression of juvenile cuttlefish (Sepia pharaonis) under salinity stress. Int J Biol Macromol 113:881-888

Zheng XD, Qian YS, Liu C, Li Q (2014) Octopus minor. In: Iglesias J, Fuentes L, Villanueva R (eds) Cephalopod Culture. Springer, Dordrecht, pp 415-426
Open Access This chapter is licensed under the terms of the Creative Commons Attribution 4.0 International License (http://creativecommons. org/licenses/by/4.0/), which permits use, sharing, adaptation, distribution and reproduction in any medium or format, as long as you give appropriate credit to the original author(s) and the source, provide a link to the Creative Commons licence and indicate if changes were made.
The images or other third party material in this chapter are included in the chapter's Creative Commons licence, unless indicated otherwise in a credit line to the material. If material is not included in the chapter's Creative Commons licence and your intended use is not permitted by statutory regulation or exceeds the permitted use, you will need to obtain permission directly from the copyright holder. 